http://jmscr.igmpublication.org/home/

ISSN (e)-2347-176x ISSN (p) 2455-0450

crossref DOI: https://dx.doi.org/10.18535/jmscr/v8i6.30

\title{
Study of Various Risk Factors in the Patients of Acute Coronary Syndrome
}

\author{
Authors

\section{Dr Bhupinder Singh ${ }^{1}$, Dr Hardip Singh ${ }^{2}$, Dr Aman Deep Goel ${ }^{3}$,} \\ Dr Tarsem Pal Singh ${ }^{4}$
}

${ }^{1}$ Associate Professor, Department of Medicine, Government Medical College, Amritsar-143001

${ }^{2}$ Associate Professor, Department of Medicine, Government Medical College, Amritsar-143001

${ }^{3}$ Junior Resident, Department of Medicine, Government Medical College, Amritsar-143001

${ }^{4}$ Professor, Department of Medicine, Government Medical College, Amritsar-143001

Corresponding Author

Dr Hardip Singh

Associate Professor, Department of Medicine, Government Medical College, Amritsar-143001, India

\begin{abstract}
Introduction: Present work was aimed to study the correlation of various risk factors like age, sex, weight, hypertension and history of smoking with left ventricular function in patients of NSTEMI, STEMI and unstable angina. This study was carried out in 120 patients of acute coronary syndrome, presenting to Guru Nanak Dev Hospital attached to Government Medical College, Amritsar. The study protocol was approved by the institutional ethics committee before initiation of the study.

Material and Methods: Present work is a prospective observational study to determine correlation between the various risk factors in patients with acute coronary syndrome. The data was collected from the patients and recorded in a prepared Case Report Form. Demographic details, medical history, information on exercise, diet, substance use, and hospitalization details were collected. After relevant history and thorough clinical examination, weight, blood pressure were measured and echocardiography was also performed.

Results: In the present study, the data showcases the relationship between hypertension and various echocardiographic parameters in patients with acute coronary syndrome. Observations of the present study show the correlation between the high blood pressure and ejection fraction of individuals of NSTEMI, STEMI and Unstable angina.

Conclusions: The data concludes that hypertension is more closely related to LV function as assessed by ejection fraction. As our data demonstrated a significant correlation between high blood pressure and reduced EF, hypertension is the very significant marker of the development of acute coronary syndrome.

Keywords: Hypertension, Smoking, Acute coronary syndrome, Unstable angina, STEMI, NSTEMI.
\end{abstract}

\section{Introduction}

Cardiovascular disease is a frequent finding India. Acute myocardial infarction (AMI) is worldwide and it is most common cause of death. Coronary artery disease (CAD) prevalence has been increasing in rural India as well as in urban devastatingly the most important form of ischemic heart disease which continues to be the most important cause of death in the industrialized as 
well as developing countries like India, despite there being lot of progress in their prevention, detection and treatment over last 30 years. Hence, myocardial infarction remains a significant health problem.

The acute manifestation of CAD is Acute Coronary Syndrome (ACS), subdivided into sudden cardiac death, Non ST elevation ACS (NSTEACS) and STelevation myocardial infarction (STEMI). The NSTEACS is further subdivided into Non STelevation myocardial infarction (NSTEMI) and Unstable angina (UA). ST elevation myocardial infarction (STEMI) is caused by acute occlusion of a major coronary artery usually due to disruption of an atherosclerotic plaque with subsequent formation of an occluding thrombus ${ }^{[1]}$. Effective and rapid restoration of blood flow to ischemic myocardial tissue is the most important initial goal in the treatment of patients with STEMI.

Certain primary risk factors have been identified with the development of atherosclerotic coronary artery disease and myocardial infarction: dyslipidemia, diabetes mellitus, hypertension, smoking, male gender, obesity and family history of atherosclerotic arterial disease. In presence of any risk factor, the relative risk of developing atherosclerotic coronary artery disease doubles. Many of the modifiable risk factors like physical activity, cessation of tobacco use, control of hypertension and diabetes mellitus are associated with lower risk profile and reduce the incidence of heart attack. Non-modifiable risk factors include age, gender and family history, which are considered to be reflecting a genetic predisposition. Creatine Kinase-MB fraction is a cardiac marker used to assist diagnosis of an acute myocardial infarction. It measures the blood level of Creatine Kinase Myocardial Band (CK-MB). Its levels can be detected within 3 to 8 hours of the onset of chest pain, peak within 12 to 24 hours, and usually return to baseline levels within 24 to 48 hours. Apart from this medical societies also agree that cardiac troponin is the biomarker of choice to facilitate the diagnosis of ACS ${ }^{[2,3,4]}$. The advantage of cardiac troponin over other biomarkers is based on its cardiac specificity. The aims and objectives of present study were to determine the correlation between various risk factors and left ventricular function in patients with acute STEMI, NSTEMI and Unstable Angina. The study protocol was approved by the institutional ethics committee before initiation of the study.

\section{Material and Methods}

Present work is a prospective observational study, conducted at Department of Medicine, Government Medical College, Amritsar. This study aims to determine correlation between hypertension, smoking history and outcome in patients with acute coronary syndrome. The subjects were consecutive patients who presented with a diagnosis of ACS, at the hospital. Once the patients met the inclusion and exclusion criteria as defined, they were enrolled in the study after signing the informed consent. The data was collected from the patients and recorded in a prepared Case Report Form Demographic details, medical history, information on exercise, diet, substance use, and hospitalization details was collected. The diagnosis of ACS was made by all or any one of the following methods:

Chest pain/discomfort defined as any symptom of chest discomfort, sensation or pressure, or tightness; or arm, neck, or jaw pain occurring before hospital arrival or preceding a diagnosis of acute MI, NSTEMI or unstable angina. The chest pain/discomfort variable was classified as present or absent before admission, during admission, or both and was included (but was not limited to) in patients presenting with shortness of breath, nausea/vomiting, palpitations, syncope, or cardiac arrest.

All cases were divided into following groups:

1. STEMI patients were defined as having chest pain for at least 20 minute with the following electrocardiography changes: ST-segment elevation $>2 \mathrm{~mm}$ in 2 contiguous precordial leads or $>1 \mathrm{~mm}$ in 2 limb leads, new left bundle branch block, or electrocardiography changes compatible with true posterior MI, with elevation of cardiac enzyme levels above the 
reference range.

2. NSTEMI patient were defined as having elevation of cardiac markers (CK-MB or troponins) in the blood on admission or 6 hours of admission.

3. Unstable angina patients were defined as patients with ACS in whom there is no detectable release of the enzymes and biomarkers of myocardial necrosis (CK-MB or troponins)

Time frame of Study- Data was collected for a period of 1 year and 4 months (from June 2018 to October 2019)

Inclusion Criteria- All patients included in the study satisfied the following criteria:

a) Patients with ACS.

b) Patients who were willing to sign an informed consent

\section{Exclusion Criteria -}

a. Patients with other conditions known to modify serum CRP such as:

- Septicaemia

- Advanced liver disease

- Other inflammatory conditions such as chronic obstructive pulmonary disease, bronchitis.

Data Collection - The data collection was done on prepared Case records. The following information was collected from the patients who satisfy the inclusion criteria and were enrolled in the study.

- Demographic Details: The demographic details of the patient such as age (in years). Height (in centimeters), weight (in kilograms) and Body mass index were collected.

- Medical History: The occurrence of Diabetes Mellitus, Hypertension and Dyslipidemia were recorded by using standard methods.

- Medication History: Medication history of the patients was recorded.

- Lifestyle Factors: The level of exercise of the patient along with his/her diet and tobacco use were noted.

- Hospitalization Details: The outcome of the hospital stay, treatment variables were recorded. The following parameters were collected;
$>$ A list of presenting complaints.

$>$ Details of hospital admission (in and out date)

$>$ List of the diagnostic tests performed before and during the hospital stay, such as ECG, $2 \mathrm{D} \mathrm{ECHO}^{[5,6]}$.

$>$ List of blood tests performed before and during the hospital visits per the practice (e.g.: Hemoglobin, total count, red blood cell, differential count, platelets, random blood sugar, serum creatinine, blood urea nitrogen (BUN), lipid profile, hs-CRP, troponin $\mathrm{T}$ ).

Cardiac death was defined as a death due to myocardial infarction, cardiac arrhythmias (sustained ventricular tachycardia, ventricular fibrillation and supraventricular tachycardia with hemodynamic compromise), cardiogenic shock, thromboembolism or congestive cardiac failure.

Samples Collection- Venous blood samples were taken from all subjects on admission up to 6 hours after admission. $5 \mathrm{ml}$ of blood without anticoagulant was collected from each participant using vacutainer system tubes (Becton-Dickinson). Samples were centrifuged at $3000 \mathrm{rpm}$ for 15 minutes for rapid serum separation.

Laboratory Measurements- Left ventricular function in all the patients was assessed by echocardiography with the help of GE and Philips EPIC-7 machines.

Data Collection and Statistical Analysis- Data was entered in the prepared Case Report Forms. Statistical analysis was performed after checking the data consistency. All the qualitative data was described as simple frequencies with percentage. Quantitative data was expressed as mean, range, and 95 percent confidence limits. Descriptive statistics is calculated for all variables. SPSS-22 version of software was used, released 2013, Armonk, NY: IBM Corp.

- Difference in mean were tested using t-test or Mann-Whitney U test as appropriate.

- Differences in proportion were assessed using Chi-square or Fisher's exact test. 
- For all tests, 2 sided p-value of 0.05 or less was considered significant.

\section{Observation}

Table 1 Distribution of age group in patients of NSTEMI, STEMI and Unstable Angina

\begin{tabular}{|c|c|c|c|c|c|c|c|c|}
\hline \multirow[t]{3}{*}{ Age group } & \multicolumn{6}{|c|}{ Diagnosis } & \multicolumn{2}{|c|}{ Total } \\
\hline & \multicolumn{2}{|c|}{ NSTEMI } & \multicolumn{2}{|c|}{ STEMI } & \multicolumn{2}{|c|}{\begin{tabular}{|c|} 
UNSTABLE \\
ANGINA
\end{tabular}} & \multirow[t]{2}{*}{ No. } & \multirow[t]{2}{*}{$\%$} \\
\hline & No. & $\%$ & No. & $\%$ & No. & $\%$ & & \\
\hline $20-40$ & 2 & 5.00 & 2 & 5.00 & 6 & 15.00 & 10 & 8.33 \\
\hline $41-60$ & 24 & 60.00 & 25 & 62.50 & 24 & 60.00 & 73 & 60.83 \\
\hline $61-80$ & 14 & 35.00 & 13 & 32.50 & 10 & 25.00 & 37 & 30.84 \\
\hline Total & 40 & 100.0 & 40 & 100.0 & 40 & 100.00 & 120 & 100.0 \\
\hline Mean & \multicolumn{2}{|c|}{$58.28 \pm 10.78$} & \multicolumn{2}{|c|}{$59.13 \pm 9.43$} & \multicolumn{2}{|c|}{$53.55 \pm 12.40$} & \multicolumn{2}{|c|}{$56.98 \pm 11.12$} \\
\hline $\mathrm{p}$-value & \multicolumn{8}{|c|}{0.053} \\
\hline
\end{tabular}

Table-1 shows the distribution of individuals of NSTEMI, STEMI and Unstable angina according to age. Number of patients in 20-40 years age group were $2(5 \%)$ in NSTEMI, $2(5 \%)$ in STEMI and $6(15 \%)$ in Unstable angina. Number of patients in 41-60 years age group were $24(60 \%)$ in NSTEMI, 25 (62.50) in STEMI and $24(60 \%)$ in Unstable angina. Number of patients in 61-80 years age group were 14 (35\%) in NSTEMI, 13 (32.50\%) in STEMI and 10(25\%) in Unstable angina. The mean age of patients was 58.28 years in NSTEMI, 59.13 years in STEMI and 56.98 yrs in Unstable angina which was found to be statistically non significant between the groups $(p=0.053)$.

Table 2 Distribution of the patients across the groups depending on sex

\begin{tabular}{|l|c|c|c|c|c|c|c|c|}
\hline \multirow{3}{*}{ Sex } & \multicolumn{6}{|c|}{ Diagnosis } & \multicolumn{2}{|c|}{ Total } \\
\cline { 2 - 8 } & \multicolumn{2}{|c|}{ NSTEMI } & \multicolumn{2}{|c|}{ STEMI } & \multicolumn{2}{c|}{$\begin{array}{c}\text { UNSTABLE } \\
\text { ANGINA }\end{array}$} & No. & $\%$ \\
\cline { 2 - 8 } & No. & $\%$ & No. & $\%$ & No. & $\%$ & & \\
\hline Female & 20 & 50.00 & 19 & 47.50 & 22 & 55.00 & 61 & 50.83 \\
\hline Male & 20 & 50.00 & 21 & 52.50 & 18 & 45.00 & 59 & 49.17 \\
\hline Total & 40 & 100.00 & 40 & 100.0 & 40 & 100.00 & 120 & 100.00 \\
\hline
\end{tabular}

Table- 2 shows distribution of individuals according to sex. Out of total 40 patients in each group, males were $20(50 \%), 21(52.50)$ and $18(45 \%)$ in NSTEMI, STEMI and unstable angina respectively and females were 20 (50\%), 19 (47.50\%) and 22 (55\%) in NSTEMI, STEMI and unstable angina respectively.
Table 3 Distribution of the patients across the groups depending on weight

\begin{tabular}{|l|c|c|c|c|c|c|c|c|}
\hline \multirow{2}{*}{$\begin{array}{l}\text { Age } \\
\text { group }\end{array}$} & \multicolumn{6}{|c|}{ Diagnosis } & \multicolumn{2}{|c|}{ Total } \\
\cline { 2 - 8 } & \multicolumn{2}{|c|}{ NSTEMI } & \multicolumn{2}{|c|}{ STEMI } & \multicolumn{2}{c|}{$\begin{array}{c}\text { UNSTABLE } \\
\text { ANGINA }\end{array}$} & No. & $\%$ \\
\cline { 2 - 8 } & No. & $\%$ & No. & $\%$ & No. & $\%$ & & \\
\hline $40-60$ & 10 & 25.00 & 15 & 37.5 & 11 & 27.50 & 36 & 30.00 \\
\hline $61-80$ & 22 & 55.00 & 23 & 57.50 & 22 & 55.00 & 67 & 55.83 \\
\hline$>80$ & 8 & 20.00 & 2 & 5.00 & 7 & 17.50 & 17 & 14.17 \\
\hline Total & 40 & 100.0 & 40 & 100.0 & 40 & 100.00 & 120 & 100.0 \\
\hline Mean & $71.50 \pm 16.01$ & $65.83 \pm 9.93$ & $69.00 \pm 10.44$ & $68.78 \pm 12.55$ \\
\hline p-value & \multicolumn{8}{|c|}{0.053} \\
\hline
\end{tabular}

Table-3 shows the distribution of individuals of NSTEMI, STEMI and Unstable angina according to weight. Number of patients in $40-60 \mathrm{~kg}$ weight group were $10(25 \%)$ in NSTEMI, $15(37.50 \%)$ in STEMI and $11(27.50 \%)$ in Unstable angina. Number of patients in $60-80 \mathrm{~kg}$ weight group were $22(55 \%)$ in NSTEMI, $23(57.50 \%)$ in STEMI and $22(55 \%)$ in Unstable angina. Number of patients in $>80 \mathrm{~kg}$ weight group were $8(20 \%)$ in NSTEMI, 2 (5\%) in STEMI and 7 (17.50\%) in Unstable angina. The mean weight of patients was $71.50 \mathrm{kgs}$ in NSTEMI, $65.83 \mathrm{kgs}$ in STEMI and $69.0 \mathrm{kgs}$ in Unstable angina. $(p=0.128)$

Table 4 Distribution of the patients across the groups depending on smoking

\begin{tabular}{|c|c|c|c|c|c|c|c|c|}
\hline \multirow{3}{*}{$\begin{array}{l}\text { Smoki } \\
\text { ng }\end{array}$} & \multicolumn{6}{|c|}{ Diagnosis } & \multicolumn{2}{|c|}{ Total } \\
\hline & \multicolumn{2}{|c|}{ NSTEMI } & \multicolumn{2}{|c|}{ STEMI } & \multicolumn{2}{|c|}{$\begin{array}{c}\text { UNSTABLE } \\
\text { ANGINA }\end{array}$} & \multirow[t]{2}{*}{ No. } & \multirow[t]{2}{*}{$\%$} \\
\hline & No. & $\%$ & No. & $\%$ & No. & $\%$ & & \\
\hline No & 34 & 85.00 & 31 & 77.50 & 32 & 80.00 & 97 & 80.83 \\
\hline Yes & 6 & 15.00 & 9 & 22.50 & 8 & 20.00 & 23 & 23.17 \\
\hline Total & 40 & 100.00 & 40 & 100.0 & 40 & 100.00 & 120 & 100.0 \\
\hline
\end{tabular}

\section{Figure-1}

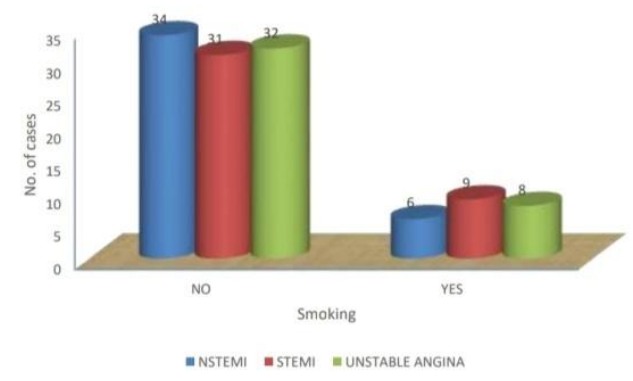

Table-4 and figure-1 show the distribution of individuals of NSTEMI, STEMI and Unstable angina according to their smoking habit. The number of smokers was $6(15 \%)$ in NSTEMI, 9 $(22.50 \%)$ in STEMI and $8(20 \%)$ in Unstable 
angina. Out of all patients taken for study, 23 $(19.17 \%)$ had history of smoking.

Chi-Square 0.75 , d.f. $=2, \mathrm{P}=0.6873$

Table 5 Distribution of the patients across the groups depending on hypertension

\begin{tabular}{|l|c|c|c|c|c|c|c|c|}
\hline \multirow{3}{*}{ Hypertension } & \multicolumn{6}{|c|}{ Diagnosis } & \multicolumn{2}{c|}{ Total } \\
\cline { 2 - 8 } & \multicolumn{2}{|c|}{ NSTEMI } & \multicolumn{2}{|c|}{ STEMI } & \multicolumn{2}{c|}{$\begin{array}{c}\text { UNSTABLE } \\
\text { ANGINA }\end{array}$} & \multirow{2}{*}{ No. } & \\
\cline { 2 - 8 } & No. & $\%$ & No. & $\%$ & No. & $\%$ & & \\
\hline No & 11 & 27.5 & 8 & 20.0 & 36 & 47.50 & 55 & 45.83 \\
\hline Yes & 29 & 72.5 & 32 & 80.0 & 4 & 52.50 & 65 & 54.17 \\
\hline Total & 40 & 100.00 & 40 & 100.0 & 40 & 100.00 & 120 & 100.00 \\
\hline
\end{tabular}

\section{Figure-2}

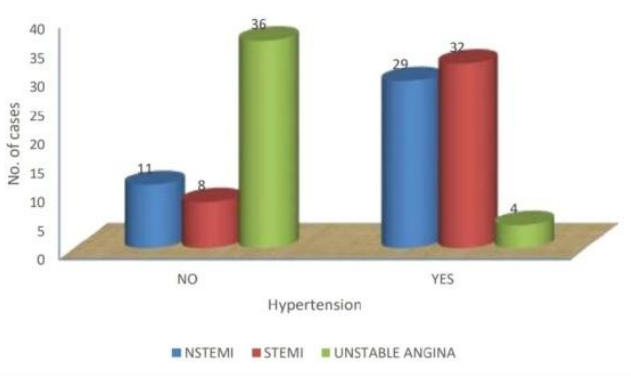

Table-5 and figure-2 shows the distribution of individuals of NSTEMI, STEMI and Unstable angina according to their history of hypertension. The number of hypertensives was 29 (72.50\%) in NSTEMI, $32(80 \%)$ in STEMI and $4(10 \%)$ in Unstable angina. Out of all patients taken for study, $65(54.17 \%)$ had history of hypertension.

Chi-Square 47.6, d.f. $=2, \mathrm{P}=0.0001$.

Table 6 Systolic blood pressure

\begin{tabular}{|l|c|c|c|}
\hline $\begin{array}{l}\text { Systolic } \\
\text { Blood } \\
\text { Pressure }\end{array}$ & NSTEMI & STEMI & $\begin{array}{c}\text { UNSTABLE } \\
\text { ANGINA }\end{array}$ \\
\cline { 2 - 4 } & & \multicolumn{3}{|c|}{ Diagnosis } \\
\hline Mean & $137.65 \pm 18.81$ & $136.60 \pm 24.91$ & $113.45 \pm 16.31$ \\
\hline p-value & \multicolumn{3}{|c|}{0.001} \\
\hline
\end{tabular}

\section{Figure-3}

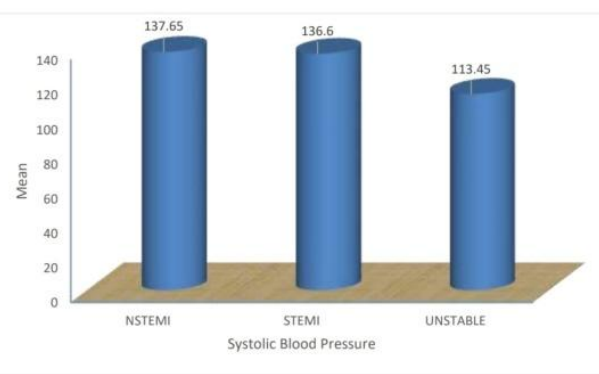

Table- 6 and figure- 3 shows the average systolic blood pressure of individuals of NSTEMI, STEMI and Unstable angina. The average systolic blood pressure was $137.65 \pm 18.81 \mathrm{mmHg}$ in NSTEMI, $136.60 \pm 24.91$ in STEMI and $113.45 \pm 16.31$ in Unstable angina.

Table 7 Diastolic blood pressure

\begin{tabular}{|l|c|c|c|}
\hline $\begin{array}{l}\text { Diastolic } \\
\text { blood } \\
\text { pressure }\end{array}$ & \multicolumn{3}{|c|}{ Diagnosis } \\
\cline { 2 - 4 } & NSTEMI & STEMI & $\begin{array}{l}\text { UNSTABLE } \\
\text { ANGINA }\end{array}$ \\
\hline Mean & $91.25 \pm 15.03$ & $86.75 \pm 15.03$ & $74.85 \pm 12.45$ \\
\hline p-value & \multicolumn{3}{|c|}{0.001} \\
\hline
\end{tabular}

\section{Figure-4}

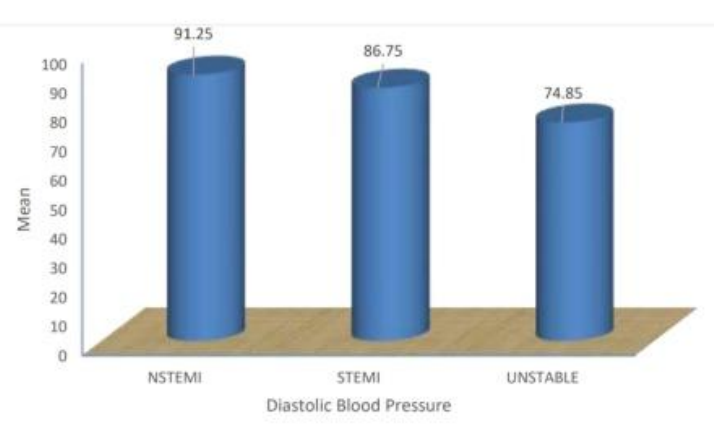

Table-7 and figure- 4 shows the average diastolic blood pressure of individuals of NSTEMI, STEMI and Unstable angina. The average diastolic blood pressure was $91.25 \pm 15.03 \mathrm{mmHg}$ in NSTEMI, $86.75 \pm 15.03$ in STEMI and $74.85 \pm 12.45$ in Unstable angina.

Table 8 Ejection fraction

\begin{tabular}{|l|c|c|c|}
\hline \multirow{2}{*}{$\begin{array}{l}\text { Ejection } \\
\text { fraction }\end{array}$} & \multicolumn{3}{|c|}{ Diagnosis } \\
\cline { 2 - 4 } & NSTEMI & STEMI & $\begin{array}{c}\text { UNSTABLE } \\
\text { ANGINA }\end{array}$ \\
\hline Mean & $49.00 \pm 9.43$ & $45.05 \pm 9.36$ & $54.08 \pm 10.94$ \\
\hline p-value & \multicolumn{3}{|c|}{0.002} \\
\hline
\end{tabular}

Table-8 shows the mean ejection fraction of individuals of NSTEMI, STEMI and Unstable angina. The mean ejection fraction was $49.00 \pm 9.43$ $\mathrm{mmHg}$ in NSTEMI, 45.05 \pm 9.36 in STEMI and $54.08 \pm 10.94$ in Unstable angina.

\section{Discussion}

Acute coronary syndrome (ACS) refers to any group of clinical symptoms compatible with acute myocardial ischemia and includes unstable angina 
(UA), non-ST-segment elevation myocardial infarction (NSTEMI), and ST-segment elevation myocardial infarction (STEMI). ACS has been divided into three clinical categories according to the presence or absence of ST-segment elevation on the initial ECG, together with measurement of myocardial biomarkers, such as troponin or creatine kinase. In ST-elevation myocardial infarction (STEMI) the ECG shows persistent STsegment elevation in two or more anatomically contiguous leads. Unstable angina and non-STelevation myocardial infarction (NSTEMI) represent a continuum of pathology, differing mainly by the presence of markers of myocardial damage in NSTEMI. Hypertension, overweight, diabetes mellitus, dyslipidemia, smoking are some of the most common risk factors identified with the development of Acute coronary syndrome.

This study was aimed to study the correlation of hypertension with left ventricular function in patients of NSTEMI, STEMI and unstable angina. The present study was carried out in 120 patients of acute coronary syndrome, presenting to Guru Nanak Dev Hospital attached to Government Medical College, Amritsar for the study. The subjects were selected according to inclusion and exclusion criteria. The study protocol was approved by the institutional ethics committee before initiation of the study. Informed consent was obtained from each patient before enrolling. After relevant history and thorough clinical examination, height, weight and BMI were measured. Systolic and diastolic blood pressure was measured with sphygmomanometer.

In the present study, the distribution of individuals of NSTEMI, STEMI and Unstable angina according to their smoking habit was $6(15 \%)$ in NSTEMI, $9(22.50 \%)$ in STEMI and $8(20 \%)$ in Unstable angina. According to an observational study by Himbert D et. al. ${ }^{[7]}$.Smokers were more frequently diagnosed with ST-segment elevation myocardial infarction than former smokers and non-smokers.

In the present study, the distribution of individuals of NSTEMI, STEMI and Unstable angina according to their history of hypertension was 29 $(72.50 \%)$ in NSTEMI, $32(80 \%)$ in STEMI and 4 $(10 \%)$ in Unstable angina. Out of all patients taken for study, 65 (54.17. \%) had history of hypertension. According to a study by Picariello C et $\mathrm{al}^{[8]}$. ACS patients with hypertension represent a subset at higher risk since they are more often older and with higher co morbidities and a strict follow up should be recommended in ACS patients with hypertension with close monitoring of adherence to drug administration. Grandi (2007) ${ }^{[9]}$ and Pedrinelli $(2012)^{[10]}$ also reported similar correlation of hypertension and acute coronary syndrome. These studies support the findings of present author.

In the present study, the mean ejection fraction of individuals of NSTEMI, STEMI and Unstable angina was $49.00 \pm 9.43 \mathrm{mmHg}$ in NSTEMI, $45.05 \pm 9.36$ in STEMI and 54.08 \pm 10.94 in Unstable angina. The study presents data regarding the relationship between hypertension and various echocardiographic parameters in patients with acute coronary syndrome. The data led us to the conclusion that hypertension is more closely related to $\mathrm{LV}$ function as assessed by ejection fraction. As our data demonstrated a significant correlation between high blood pressure and reduced $\mathrm{EF}$, may be a marker of $\mathrm{LV}$ dysfunction.

\section{Bibliography}

1. Ridker PM, Daneilson E, Fonseca FA, Genset J, Gotto AM, Kastelein JJ et al. JUPITER Study Group. Rosuvastatin to prevent vascular events in men and women with elevated C-reactive protein. N Engl J Med. 2008;359 (21):2195-207.

2. Anderson JL, Admas CD, Antman EM. ACC/AHA 2007 guidelines for the management of patients with UA/NSTEMI: a report of the ACC/AHA Task Force on practice Guidelines: developed in collaboration with the American College of Emergency Physicians, the society for Cardiovascular Angiography and Interventions, and the Society of Thoracic Surgeons: endorsed by the American 
association of Cardiovascular and pulmonary Rehabilitation and the Society for Academic Emergency medicine. Circulation. 2007;116(7)e:148-e304.

3. Bassand JP, Hamm CW, Ardissino D. Guidelines for the diagnosis and treatment of non - ST -segment elevation ACS. Eur Heart J. 2007; 28(13):1598-660.

4. Marrow DA, Cannon CP, Jesse RL. NACB Laboratory medicine Practice guidelines: clinical characteristics and utilization of biochemical markers in ACS. Clin Chem. 2007; 53(4):552-74.

5. Robert O, Bonow, Douglas L, Mann, Douglas P. Zipes. STEMI: Pathology, pathophysiology, and clinical features. Braunwald's Heart Disease: a Textbook of Cardiovascular Medicine, $9^{\text {th }}$ edition. Saunders, 2012;1087-110.

6. Yu CM, Sanderson JE, Marwick TH. Tissue Doppler imaging a new prognosticator for cardiovascular diseases. $\mathbf{J}$ Am Coll Cardiol. 2007:49:1903.

7. Himbert D, Klutman M, Steg G, White K, Gulba DC, GRACE Investigators. Cigarette smoking and acute coronary syndromes: a multinational observational study. International Journal of Cardiology. 2005;100(1):109-17.

8. Picariello C, Lazzeri C, Attana P, Chiostri M, Gensini GF, Valente S. The impact of hypertension on patients with acute coronary syndromes. International Journal of Hypertension. 2011;22:1-7.

9. Grandi AM, Laurita E, Marchesi C, Maresca A, Solbiati F, Nicolini E, Gianni M, Guasti L and Venco A. Family History of Hypertension Influences Left Ventricular Diastolic Function During Chronic Antihypertensive Therapy. Am J Hypertens 2007; 20(4):410-5.
10. Pedrinelli R, Ballo P, Fiorentini C, Denti S, Galderisi S, Ganau A, Germano G, Zaca V, Studio GD, Cuore IE, et al. Hypertension and Acute Myocardial Infarction: An Overview. 2012 Mar;13(3):194-202. 